\title{
Optimization of Rear Local Al-Contacts on High Efficiency Commercial PERC Solar Cells with Dot and Line Openings
}

\author{
Peisheng Liu, ${ }^{1}$ Xiaolong Zhang, ${ }^{1}$ Ling Sun, ${ }^{1}$ Shanshan Dai, ${ }^{1}$ \\ Chenhui Yu, ${ }^{1}$ and Xiangdong Luo ${ }^{1,2}$ \\ ${ }^{1}$ Jiangsu Key Laboratory of ASIC Design, Nantong University, Nantong, Jiangsu 226019, China \\ ${ }^{2}$ Key Laboratory of Nanodevices and Applications, Suzhou Institute of Nano-Tech and Nano-Bionics, \\ Chinese Academy of Sciences, Suzhou 215123, China \\ Correspondence should be addressed to Xiangdong Luo; 1388364@qq.com
}

Received 3 January 2014; Accepted 30 January 2014; Published 11 March 2014

Academic Editor: Wenjie Mai

Copyright (C) 2014 Peisheng Liu et al. This is an open access article distributed under the Creative Commons Attribution License, which permits unrestricted use, distribution, and reproduction in any medium, provided the original work is properly cited.

\begin{abstract}
Crystalline silicon PERCs with dot or line openings on rear surface were studied here. By measuring the minor carrier lifetimes of the PERCs with dot and line openings, passivation effects of rear surface with dot and line openings were discussed. The performance affected by dot and line openings was analyzed in detail by testing the open-circuit voltages, short-circuit current densities, fill factors, and conversion efficiencies of the PERCs. The results show that the wider space resulted in better minor carrier lifetimes on the rear surface. And the cells with a line opening space of $0.5 \mathrm{~mm}$ had an average of $0.22 \%$ improvement of conversion efficiency, compared with the cells with full-area Al-BSF. On the other hand, the dot opening PERCs exhibited only a conversion efficiency of $17.4 \%$, although there had been good rear surface reflectivity. The bad Al-Si alloy layer and large hollow densities in dot Al-contacts resulted in bad performance of the PERCs with dot openings.
\end{abstract}

\section{Introduction}

In industrial solar cell manufacturing processes, crystalline silicon solar cells (c-Si-SC) typically apply a full-area aluminum back surface field (Al-BSF) at the rear surface, which is screen-printed and sintered at temperatures of 700-900 Celsius degree [1-4]. The Al-BSF provides a good ohmic contact. However, the rear surface passivation is only moderate on p-type silicon substrates. And, with a full-area Al-BSF, the effective rear surface recombination velocities are typically large, ranging from 200 to $600 \mathrm{~cm} / \mathrm{s}$. Theoretical analysis has indicated that back light absorption and rear surface recombination losses are totally around $4 \%$ in this kind of c-Si-SC [5]. In order to improve the rear surface internal reflectivity and passivation, local Al-contacts with dielectric layer passivated rear surface, that is, passivated emitter and rear cell (PERC) architecture, are performed [69]. After $\mathrm{PClO}_{3}$ diffusion, a dielectric layer is passivated on the rear surface or both sides. Then, local windows are opened by laser or chemical etching techniques on the dielectric layer of rear surface, usually dot or line openings. And the local $\mathrm{Al}$-contacts are formed by $\mathrm{Al}$ screen printing techniques on the rear opened windows. The opened Al-contact sizes and the openings' spaces on dielectric layer have significant impact on the contact formation and the effective rear surface recombination. The reported results have shown that, regardless of dot or line openings, the conversion efficiencies of PERCs are improved up to $2 \%[10,11]$. Many researches about these had been done in laboratory, but few had been done in solar cell manufacturers.

In this work, crystalline silicon PERCs with dot and line openings of local Al-contacts were fabricated in a commercial production line. The local Al-contracts were formed on the dot or line openings of the rear surface of PERCs. The dot and line openings had the same sizes and different dot-dot or lineline spaces. By studying the minor carrier lifetimes of their local Al-contact rear surface, the open-circuit voltages $\left(V_{o c}\right)$, the short-circuit current densities $\left(J_{\mathrm{sc}}\right)$, the fill factors, and conversion efficiencies of the PERCs, wider space can result in better minor carrier lifetimes of rear surface, and the PERCs 


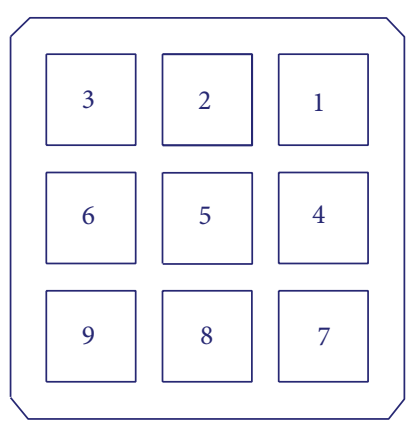

FIgURE 1: The schematic diagram of experimental wafers.

with line openings had better performance than the c-Si-SC with full-area Al-BSF and the PERCs with dot openings. Our experimental results showed that the line opening PERCs with a space of $0.5 \mathrm{~mm}$ had an average of $0.22 \%$ improvement of conversion efficiency. On the other hand, because of bad $\mathrm{Al}-\mathrm{Si}$ alloy layer and hollows existing in the dot Al-contacts, the dot opening PERCs had a bad performance, comparing with the solar cells with full-area Al-BSF and line openings.

\section{Experimental Process}

All wafers used here were p-type crystalline silicon wafers with a thickness of $200 \mu \mathrm{m}$ and bulk resistivity of $2.0 \Omega \cdot \mathrm{cm}$ around. The wafer size was $125 \mathrm{~mm} \times 125 \mathrm{~mm}$, and their entire bulk minor carrier lifetimes were in ranges of 120 to $180 \mu \mathrm{s}$, measured by microwave photoconductivity decay method. After normal cell processes, including washing, texture, and $\mathrm{POCl}_{3}$ diffusion, front and rear SiNx layers were deposited by PECVD. Then, the wafers were used to open windows on the rear surface by chemical etching technique. In our experiments, the dot opening diameter and line opening width were fixed at $100 \mu \mathrm{m}$, and only dot-dot and line-line spaces were changed. After opening, by $\mathrm{Al}$ screen printing and rapid thermal process, PERCs with different openings were fabricated out.

\section{Results and Discussion}

In order to study the PERCs with dot and line openings in commercial processes, each wafer was divided into nine areas. To the wafer with dot openings, the Number 2 to Number 8 areas were dot opening PERCs with different opening spaces. For comparison, the Number 1 area was full size Al-BSF c-Si-SC structure and the Number 9 area was not etched for Al-contact. Similarly, the same layouts were distributed for line opening wafer. Their schematic diagram was shown in Figure 1 and their space values were listed in Table 1. In our experiments, the dot opening space was changed from $0.14 \mathrm{~mm}$ to $0.51 \mathrm{~mm}$, and the line opening space was from $0.25 \mathrm{~mm}$ to $3.33 \mathrm{~mm}$.

Figure 2 showed two typical minor carrier lifetime maps of PERCs' rear surfaces ((a) line opening PERC and (b) dot opening PERC). Seen from Figure 2(a) (line opening PERCs), the minor carrier lifetimes of the full Al-BSF rear surface
TABLE 1: Line and dot opening spaces of each area on SC wafers.

\begin{tabular}{lcc}
\hline Number & Line opening space $(\mathrm{mm})$ & Dot opening space $(\mathrm{mm})$ \\
\hline 1 & Full Al-BSF & Full Al-BSF \\
2 & 0.25 & 0.14 \\
3 & 0.33 & 0.16 \\
4 & 0.5 & 0.2 \\
5 & 1.0 & 0.28 \\
6 & 1.43 & 0.33 \\
7 & 2.0 & 0.4 \\
8 & 3.33 & 0.51 \\
9 & No etching & No etching \\
\hline
\end{tabular}

(Number 1 area) were comparable with the line opening PERCs of the Number 5 to Number 8. And the minor carrier lifetimes of the PERCs' rear surface with narrow line-line spaces (Number 2 area with $0.25 \mathrm{~mm}$; Number 3 area with $0.33 \mathrm{~mm}$; Number 4 area with $0.5 \mathrm{~mm}$ ) were much shorter than the others with full-area Al-BSF and wide line-line spaces (Number 5 to Number 8 areas). At the same time, seen from Figure 2(b), the minor carrier lifetimes of dot opening PERCs had similar results. Obviously, wider dot-dot and line-line spaces had longer minor carrier lifetime, which indicated that wider spaces of local $\mathrm{Al}$-contacts resulted in better passivation effects.

Figure 3(a) showed the measured minor carrier lifetimes of nine pieces of dot opening wafers and ten pieces of line opening wafers. At the same time, the mean values of minor carrier lifetimes were also shown in Figure 3(b) according to their area number on the wafers. As mentioned above, since the PERCs with narrow space had much shorter minor carrier lifetime than the c-Si-SC with full-area Al-BSF, their measured lifetimes were not shown in Figure 3. Firstly, seen from Figure 3, line opening PERCs had better minor carrier lifetimes and passivation than the dot openings. Secondly, the PERCs with narrower space had a short minor carrier lifetime and worse passivation. On the other hand, seen from the average minor carrier lifetimes of dot and line opening PERCs as a function of space (as shown in Figure 3(b)), the lifetime was almost increased monotonously. In particular, the Number 4 area of line opening PERCs had a minor carrier lifetime of $29.5 \mu \mathrm{s}$, which was between the Number 7 and Number 8 dot opening PERCs (27 and $32.1 \mu$ s, resp.). And as we knew above, the Number 4 area of the line opening PERCs had a similar space with the Number 7 and Number 8 areas of the dot opening PERCs. Therefore, from the above analyzed results, it was indicated that the dot-dot and line-line spaces had very important effect on the rear surface passivation of PERCs. Larger space had better passivation effect.

In order to exhibit the results of PERCs with different openings, the testing results of c-Si-SC with full-area AlBSF (the 1st area in Figure 1), the PERCs with line openings of $0.5 \mathrm{~mm}$ space (the 4 th area), and the dot openings of $0.51 \mathrm{~mm}$ space (the 8 th area) were used to compare. Figure 4 showed their statistical average results of $V_{\mathrm{oc}}, J_{\mathrm{sc}}$, fill factors, and conversion efficiencies (10 pieces per group). Seen from Figure 4, the performance of the PERCs with line openings 


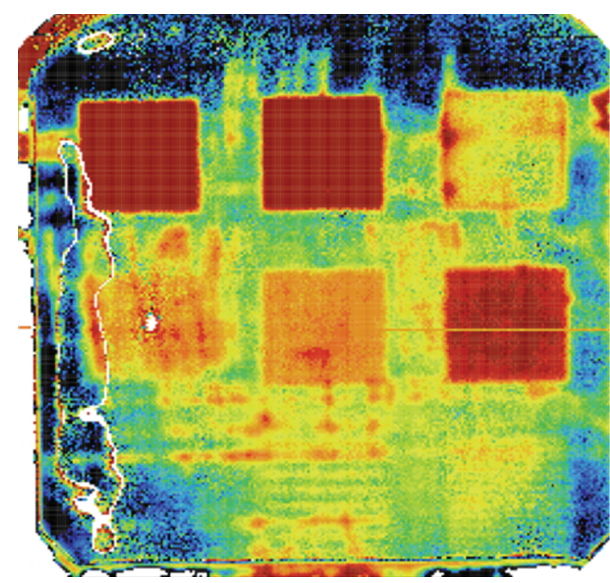

$26 \mu \mathrm{s}$
$105 \mu$

(a)

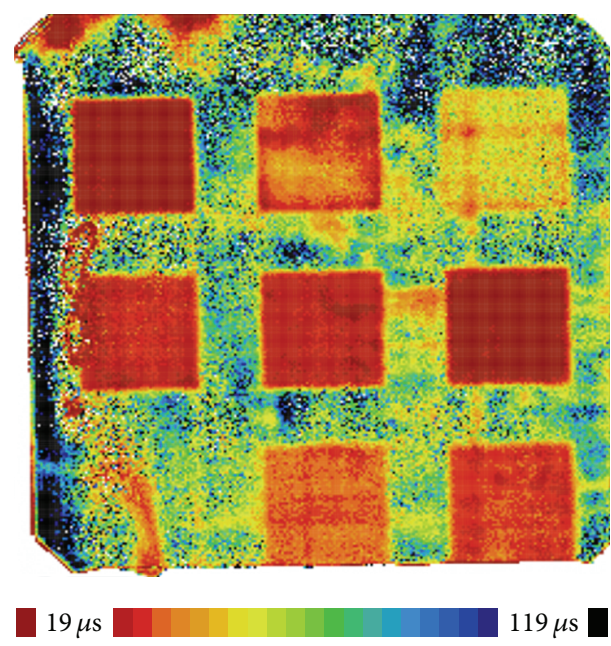

(b)

Figure 2: 2D maps of minor carrier lifetimes of PERCs with line (a) and dot (b) openings.

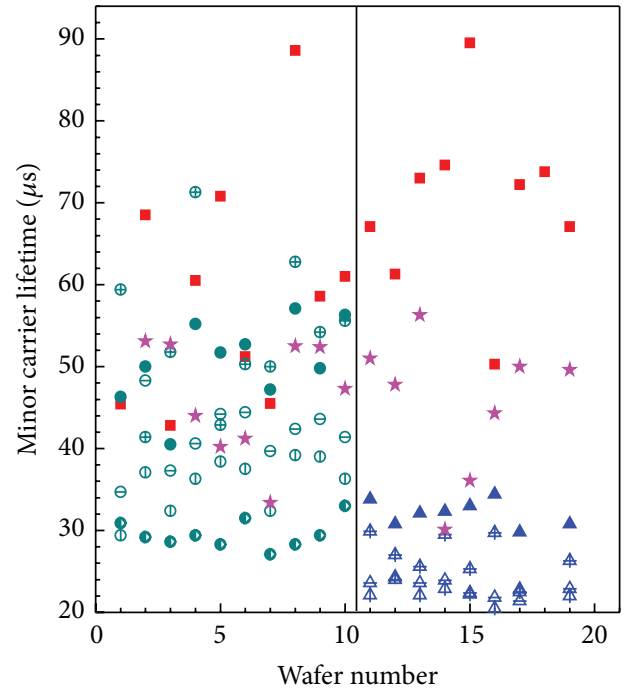

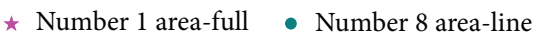
- Number 9 area-none 4 Number 5 area-dot

- Number 4 area-line $\Delta$ Number 6 area-dot

- Number 5 area-line 4 Number 7 area-dot

$\ominus$ Number 6 area-line $\Delta$ Number 8 area-dot

$\oplus$ Number 7 area-line

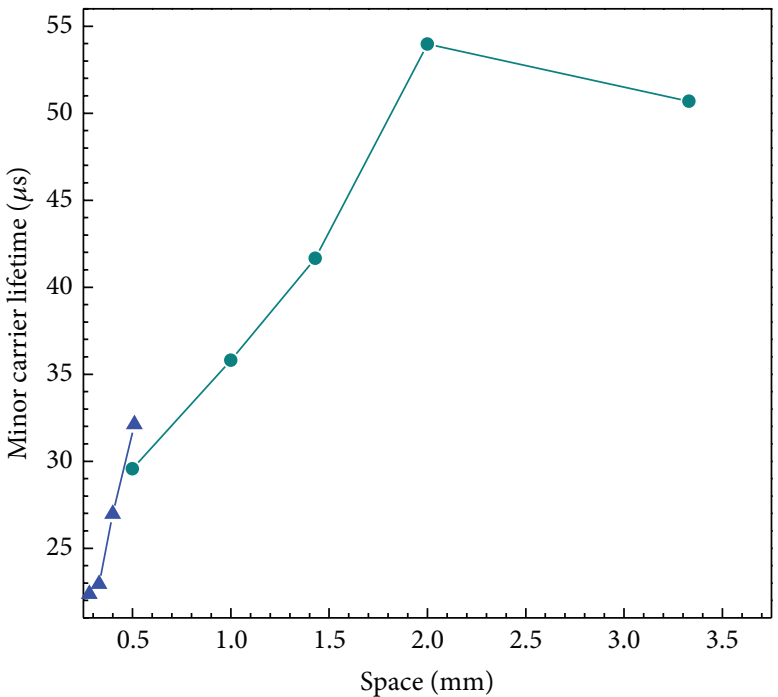

- Dot opening

- Line opening

(a)

(b)

Figure 3: (a) Statistical minor carrier lifetimes of cells with different openings; (b) statistical mean minor carrier lifetimes as a function of neighbored local-contact space.

showed better $V_{\mathrm{oc}}, J_{\mathrm{sc}}$ and conversion efficiency. In particular, the average conversion efficiency of PERCs with line openings had a $0.22 \%$ up, comparing with the cells with fullarea Al-BSF. While the PERCs with dot openings have bad performance, their average conversion efficiency had only $17.4 \%$ and $0.8 \%$ loss to the cells with the full-area Al-BSF. Therefore, although the measured total reflectivity and rear surface reflectivity of PERCs' rear surface were much better than the cells with full-area Al-BSF (as shown in Figure 5), the PERCs with dot openings exhibited still bad.

Figure 6 showed the cross sections of local Al-contacts of above PERCs with line and dot openings. Seen from the SEM pictures, the local contact with line openings had a very distinct and thick Al-Si alloy layer (Figure 6(a)), while the local contact with dot openings had only a very unclear and thin Al-Si layer. Seen from Figure 6, the average thickness of 

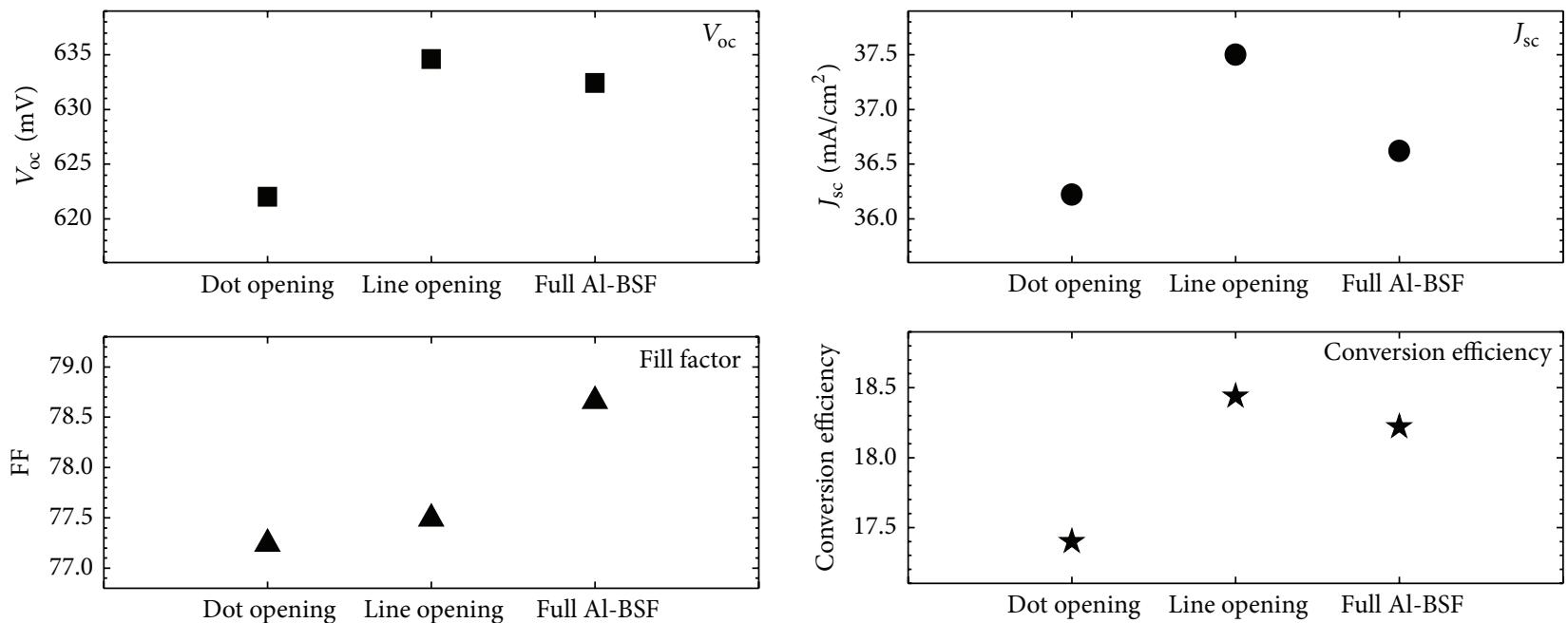

FIGURE 4: Open-circuit voltages, short-circuit current densities, fill factors, and conversion efficiencies of cells with full Al-BSF and PERCs with dot and line openings.

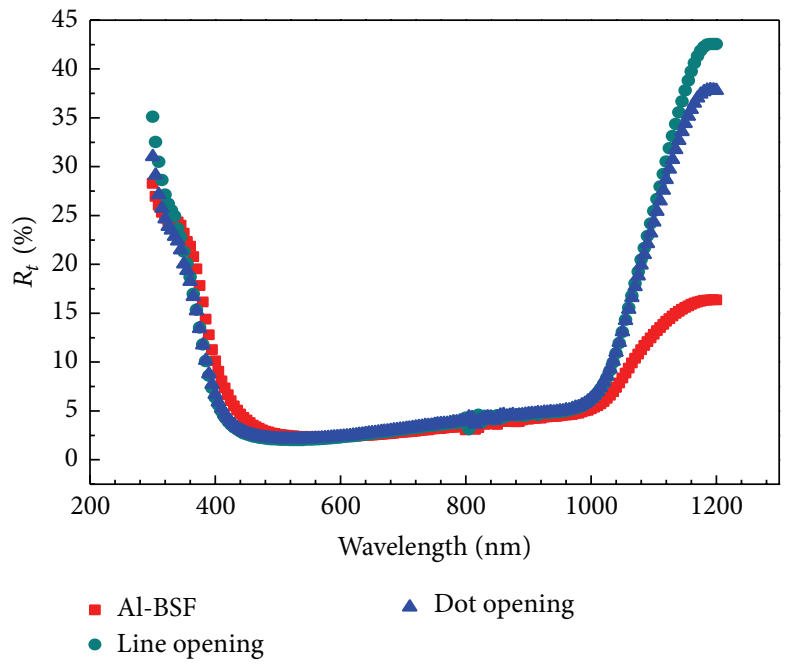

(a)

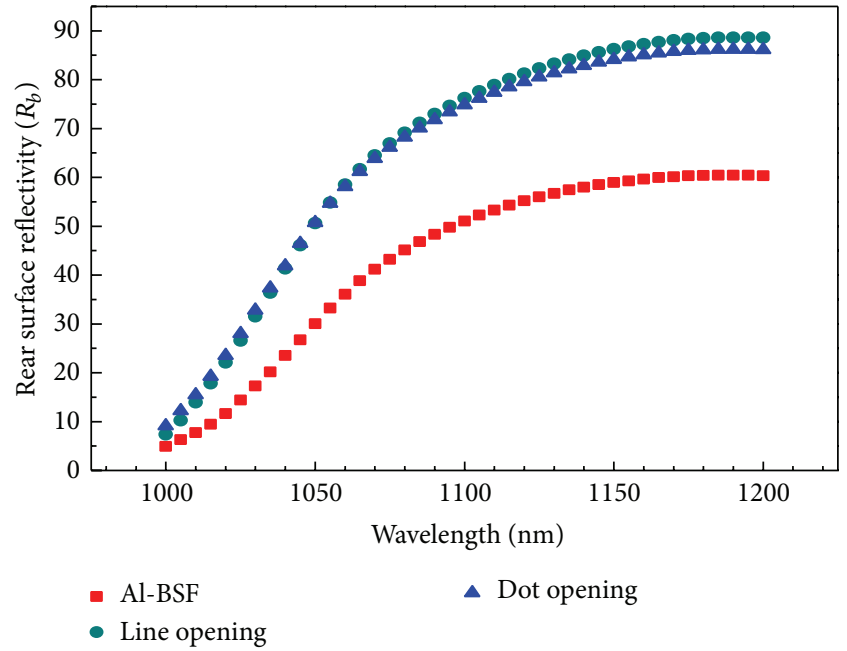

(b)

FIGURE 5: (a) Total reflectivities of cells with full Al-BSF and PERCs with dot and line openings; (b) rear surface reflectivities of cells with full Al-BSF and PERCs with dot and line openings.

the local contact with line openings was $3.9 \mu \mathrm{m}$, while the local contact with dot openings is around $0.8 \mu \mathrm{m}$. The unclear and thin Al-Si layer in the local contact of PERC resulted in worse Ohm contacts than the cells with line openings and full Al-BSF. On the other hand, both in the PERCs with line and dot openings, Kirkendall hollows were observed very often [12]. By checking large amount of cross section SEM pictures, there were almost the same hollow densities existing in the wafers of the PERCs with line and dot openings. Considered with the total Al-Si alloy surface, the PERCs with line openings had also better Ohm contact than the dot openings. Therefore, the bad Al-Si alloy layer on the local Alcontacts and large hollow densities in the dot openings might be the important factors resulting in the bad performance of the PERCs with dot openings in our testing industrial product line.

\section{Conclusions}

Crystalline silicon PERCs with local Al-contact rear surface were studied here. The local Al-contracts were formed on the dot or line openings of the rear surface by chemical etching technique. The minor carrier lifetimes of the local Al-contact rear surface with different dot-dot or line-line space were measured by microwave photoconductivity decay technique, and the open-circuit voltages short-circuit current densities, fill factors, and conversion efficiencies of the PERCs 


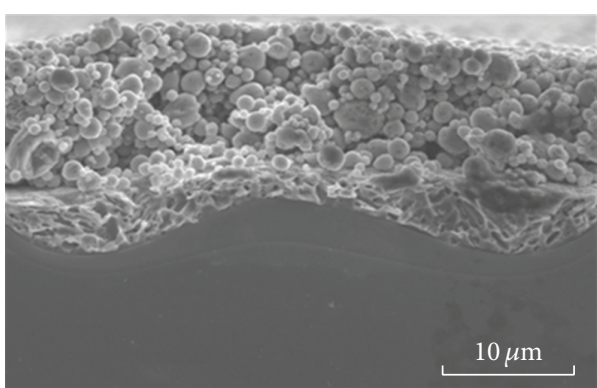

(a)

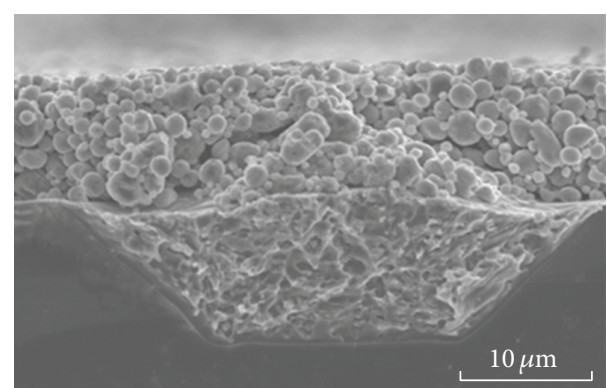

(b)

FIgURE 6: Cross section SEM pictures of PERCs with line (a) and dot (b) openings.

were measured by online solar cell module testing setup. The experimental results suggested that the wider space resulted in better minor carrier lifetimes of rear surface. And The PERCs with a line opening space of $0.5 \mathrm{~mm}$ had an average of $0.22 \%$ improvement of conversion efficiency, compared with the solar cells with full-area Al-BSF and dot openings. On the other hand, the dot opening PERCs exhibited only a conversion efficiency of $17.4 \%$, although there had been good rear surface reflectivity. The bad Al-Si alloy layer and a lot of hollows existing in dot $\mathrm{Al}$-contacts resulted in comprehensive bad performance of PERCs with dot openings.

\section{Conflict of Interests}

The authors declare that there is no conflict of interests regarding the publication of this paper.

\section{Acknowledgments}

This work was mainly done in Hanwha-Solar One in Qidong. And this work was supported by the applied basic science project of Ministry of Transport of China (Grant no. 2013319813100), the Natural Science Foundation of Jiangsu Province (Grant nos. BK2012656 and 10KJA140043), the National Natural Science Foundation of China (Grant nos. 11104150, 11274330, and 21375067), and the Open Project of Key Laboratory of Nanodevices and Applications (Grant no. 12ZD03).

\section{References}

[1] S. Gatz, T. Dullweber, and R. Brendel, "Evaluation of serious resistance losses in screen-printed solar cells with local rear contacts," IEEE Journal of Photovoltaics, vol. 1, no. 1, pp. 37-42, 2011.

[2] T. Lauermann, T. Luder, S. Scholz, B. Raabe, G. Hahn, and B. Terheiden, "Enabling dielectric rear side passivation for industrial mass production by developing lean printing-based solar cell processes," in Proceedings of the 35th IEEE Photovoltaic Specialists Conference (PVSC '10), vol. 1, pp. 28-33, Honolulu, Hawaii, USA, June 2010.

[3] J. Z. Song, S. A. Kulinich, J. Yan et al., "Epitaxial ZnO nanowireon-nanoplate structures as efficient and transferable field emitters," Advanced Materials, vol. 25, no. 40, pp. 5750-5755, 2013.
[4] H. B. Zeng, X.-W. Du, S. C. Singh et al., "Nanomaterials via laser ablation/irradiation in liquid: a review," Advanced Functional Materials, vol. 22, no. 7, pp. 1333-1353, 2012.

[5] S. Eglash, "Competition improves silicon-based solar cells," Laser Focus World, vol. 45, no. 12, pp. 38-41, 2009.

[6] Z. F. Yu, A. Raman, and S. H. Fan, "Fundamental limit of nanophotonic light trapping in solar cells," Proceedings of the National Academy of Sciences of the United States of America, vol. 107, no. 41, pp. 17491-17496, 2010.

[7] J. H. Zhao, A. H. Wang, and M. A. Green, " $24.5 \%$ efficiency silicon PERT cells on MCZ substrates and $24.7 \%$ efficiency PERL cells on FZ substrates," Progress in Photovoltaics, vol. 7, no. 6, pp. 471-474, 1999.

[8] A. W. Blakers, A. Wang, A. M. Milne, J. Zhao, and M. A. Green, "22.8\% efficient silicon solar cell," Applied Physics Letters, vol. 55, no. 13, pp. 1363-1365, 1989.

[9] J. H. Petermann, D. Zielke, J. Schmidt, F. Haase, E. G. Rojas, and R. Brendel, "19\%-efficient and $43 \mu \mathrm{m}$-thick crystalline Si solar cell from layer transfer using porous silicon," Progress in Photovoltaics, vol. 20, no. 1, pp. 1-5, 2012.

[10] T. Dullweber, S. Gatz, H. Hannebauer et al., "19.4\%-efficient large area rear-passivated screen-printed silicon solar cells," in Proceedings of the 26th European Photovoltaic Solar Energy Conference and Exhibition (EU PVSEC '11), vol. 1, pp. 811-816, Hamburg, Germany, 2011.

[11] K. Wijekoon, F. Yan, Y. Zheng et al., "Optimization of rear local contacts on high efficiency PERC solar cells structures," International Journal of Photoenergy, vol. 2013, Article ID 368403, 8 pages, 2013.

[12] E. O. Kirkendall and A. D. Smigelskas, "Diffusion of zinc in alpha brass," Transactions of the American Institute of Mining, Metallurgical and Petroleum Engineers, vol. 171, pp. 130-142, 1947. 

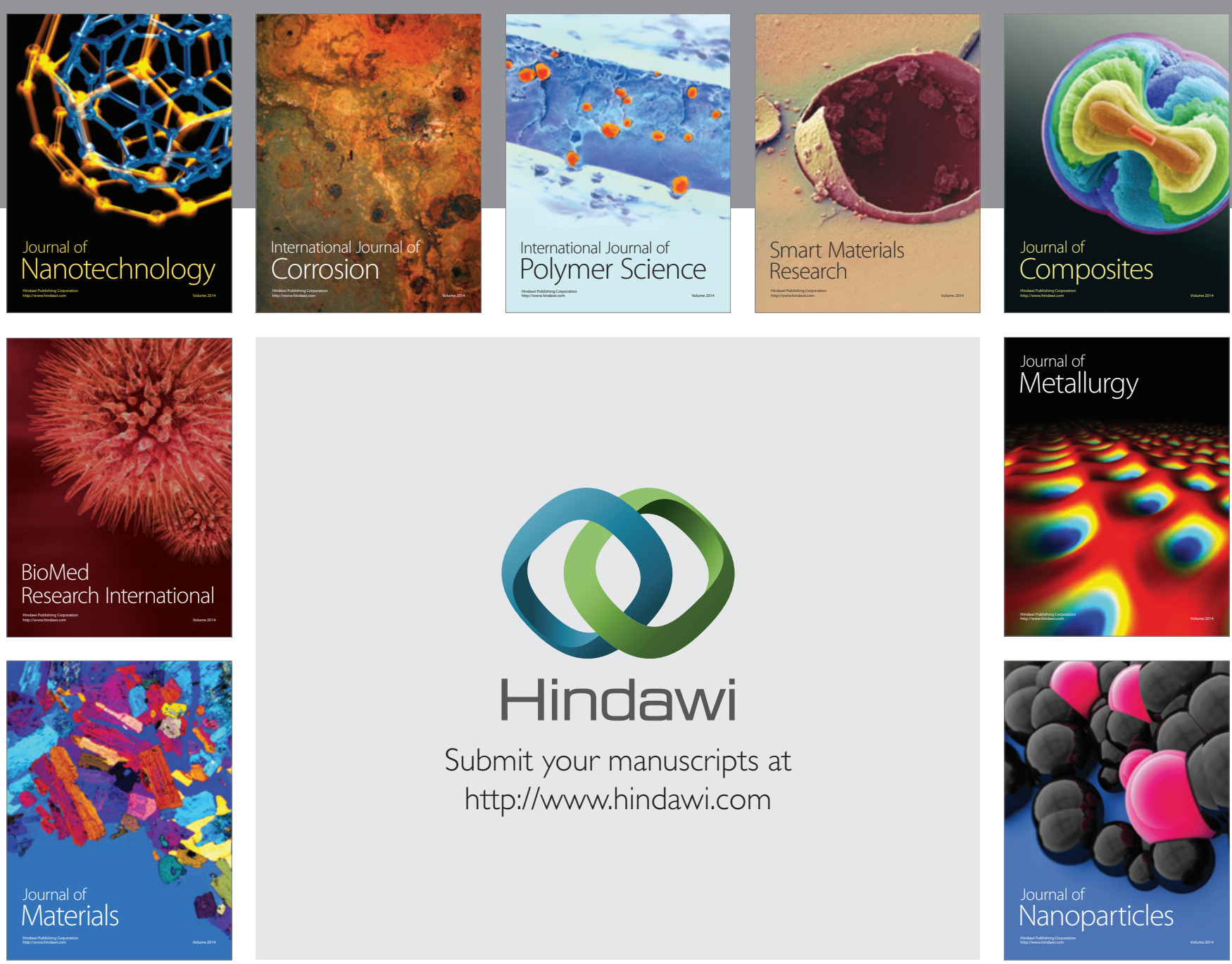

Submit your manuscripts at http://www.hindawi.com
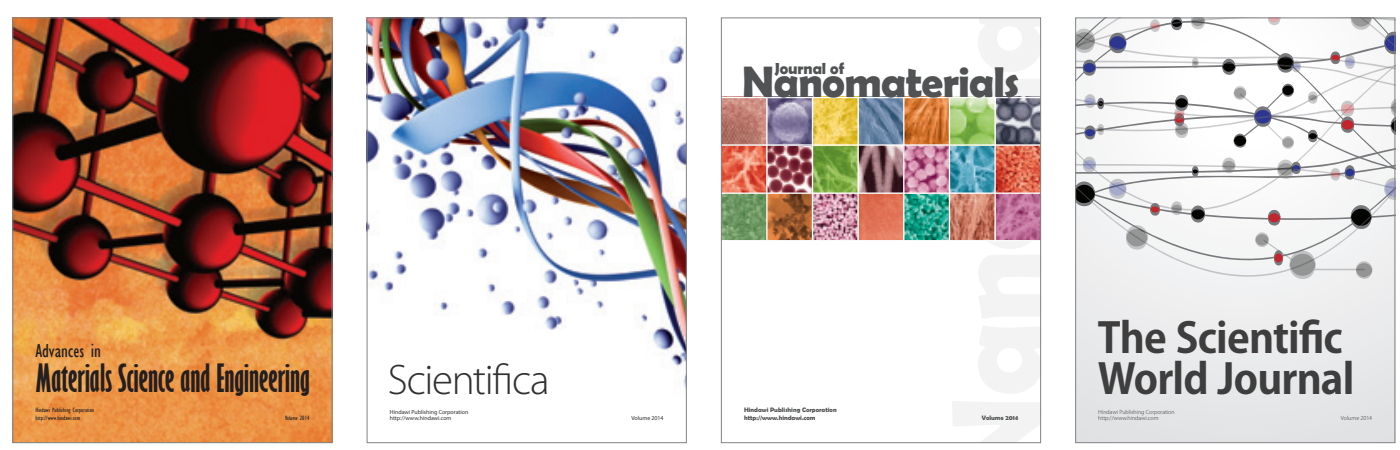

\section{The Scientific World Journal}
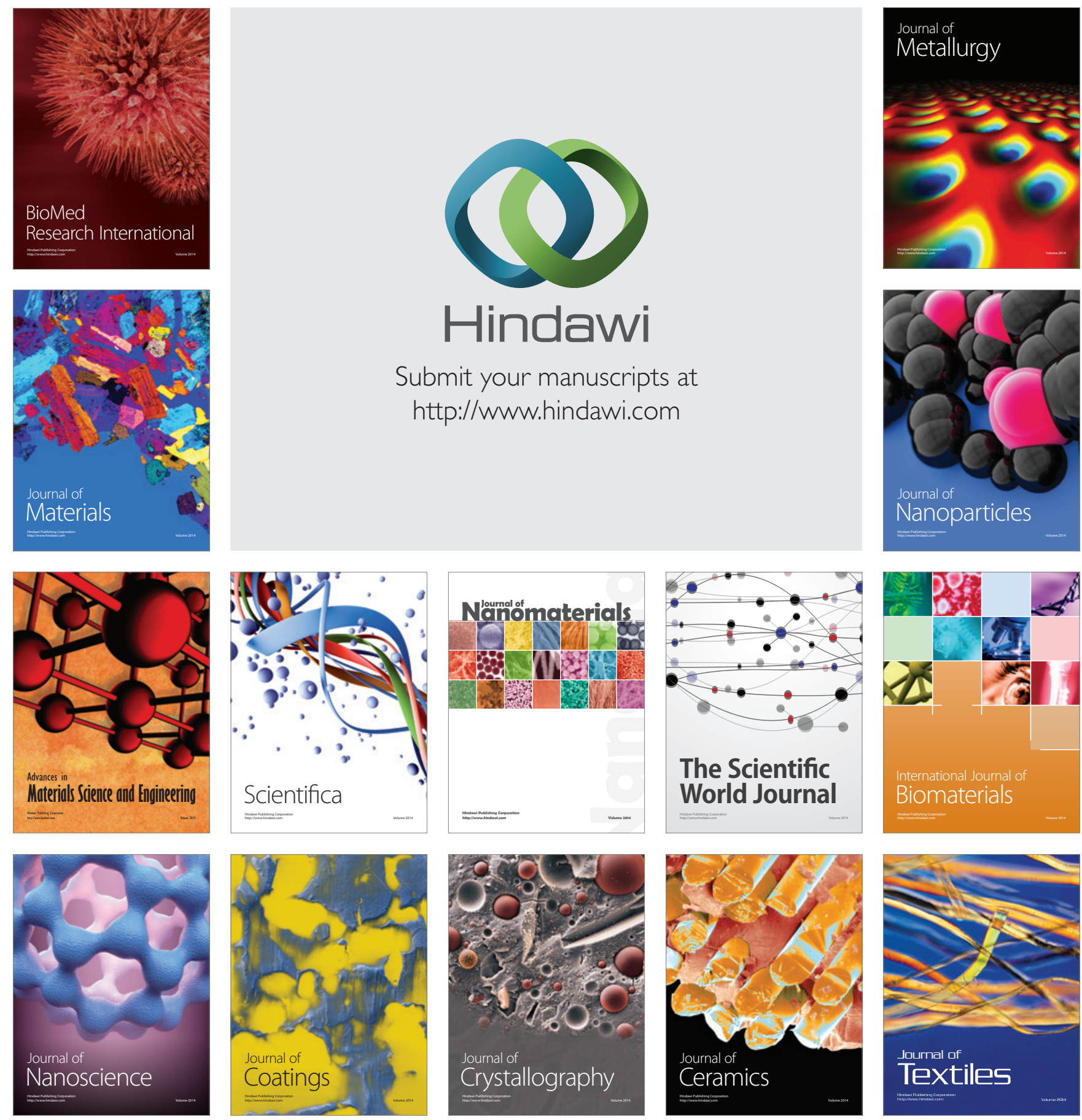